\title{
Progress report: College- based internship programs AOA, Division of Postdoctoral Training
}

W. DOUGLAS WARD, Ph.D. Chicago, Illinois
This report was developed as directed by $\mathrm{AOA}$ Board Memorandum B-March/84-3. The Board, with the adoption of this policy, authorized the development of AOA-approved internships sponsored by colleges of osteopathic medicine. The policy permitted the colleges to utilize either osteopathic or allopathic facilities, and it established several areas of compliance that the sponsoring institution must address.

\section{General summary}

In July 1986, the Board of Trustees revisited the college-based internship program, removing it from pilot status and committing increased resources to program development. Accordingly, this year the AOA Department of Education engaged in several new activities specifically designed to facilitate the continued development of college-based internships, including the Program Development Workshops underwritten by Riker Laboratories. The two Riker workshops conducted in WilkesBarre, Pennsylvania, and Los Angeles, were planned in conjunction with colleges of osteopathic medicine and targeted the hospitals they identified as potential college-sponsored training sites. The Department also coordinated a similar workshop for the University of New England College of Osteopathic Medicine (UNECOM) and provided individual consultation by phone and on site as needed.

The colleges responded to the AOA's initiative and their own internal pressures to provide positions for graduates by establishing 5 new programs between July 1986 and June 1987 inclusive of 22 approved and 16 funded positions. Colleges with existing programs requested and were approved for 17 additional positions, and funded 11 additional slots. (During the same time period, however, 1 program was discontinued, for a loss of 11 approved positions.)

By the end of the 1987-88 Intern Registration Program (IRP), therefore, there were a total of 22 college-based programs sponsored by 8 colleges of osteopathic medicine with 182 approved positions, and 154 funded positions. Of these, 145 were filled for the 1987-88 training year. Two colleges, UNECOM and Texas College of Osteopathic Medicine (TCOM), sponsored college-based intern training for the first time, joining College of Osteopathic Medicine of the Pacific (COMP), Southeastern College of Osteopathic Medicine (SECOM), Michigan State University - College of Osteopathic Medicine (MSUCOM), New York College of Osteopathic Medicine (NYCOM), Philadelphia College of Osteopathic Medicine (PCOM), and West Virginia School of Osteopathic Medicine (WVSOM).

There are also five colleges that continue to sponsor internships which were approved prior to the adoption of the college-based program policy. These colleges are Chicago College of Osteopathic Medicine (CCOM), Kirksville College of Osteopathic Medicine (KCOM), Ohio University College of Osteopathic Medicine (OUCOM), the University of Health Sciences, College of Osteopathic Medicine (UHSCOM), and PCOM. (PCOM has programs in both categories.) These programs will be addressed in a separate section of this report.

A summary of the activity at 8 institutions sponsoring college-based internships reveals the following:

(1) There are 182 approved college-based internship positions at 22 hospitals;

(2) Of the 22 hospitals 5 have AOA hospital accreditation and 17 are allopathic or mixed-staff hospitals.

(3) Of the 182 approved positions 141 were available by March $1987 ; 156$ by May 1987 .

(4) 8 of the programs are based at state-funded colleges while 14 of the programs are sponsored by private colleges.

\section{The college-based internship}

The positions initiated by COMP, SECOM, MSUCOM, NYCOM, PCOM, TCOM, WVSOM, and UNECOM are summarized in Tables 1 and $1 \mathrm{~A}$.

The number of positions approved represents approximately 11 percent of the total 1,660 AOA-approved internship positions registered on July 1 , 1987 (Fig. 1). 


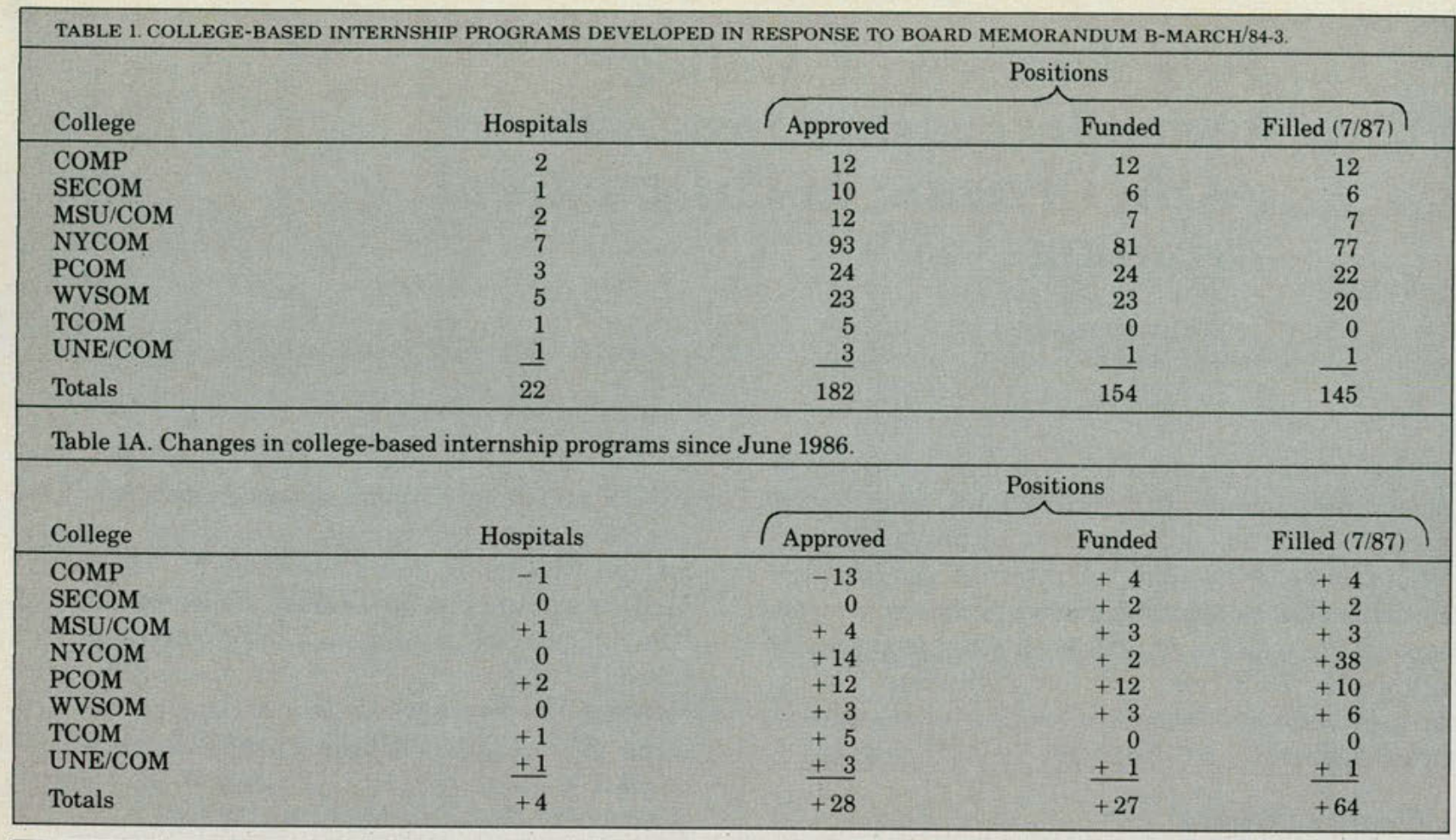

\begin{tabular}{|c|c|c|c|c|}
\hline \multirow[b]{2}{*}{ College } & \multirow[b]{2}{*}{ Hospitals } & \multicolumn{3}{|c|}{ Positions } \\
\hline & & Approved & Funded & Filled $(7 / 87))$ \\
\hline KCOM & 1 & 21 & 11 & 11 \\
\hline CCOM & 5 & 86 & 65 & 56 \\
\hline $\mathrm{UHS} / \mathrm{COM}$ & 1 & 14 & 10 & 10 \\
\hline PCOM & 1 & 30 & 30 & 30 \\
\hline OUCOM & 1 & 5 & 5 & 5 \\
\hline UMDNJ/SOM & $\underline{3}$ & 60 & 48 & 48 \\
\hline Totals & 12 & 216 & 169 & 160 \\
\hline
\end{tabular}

Table 2A. Changes in the other college-sponsored intern training program since May 1986.

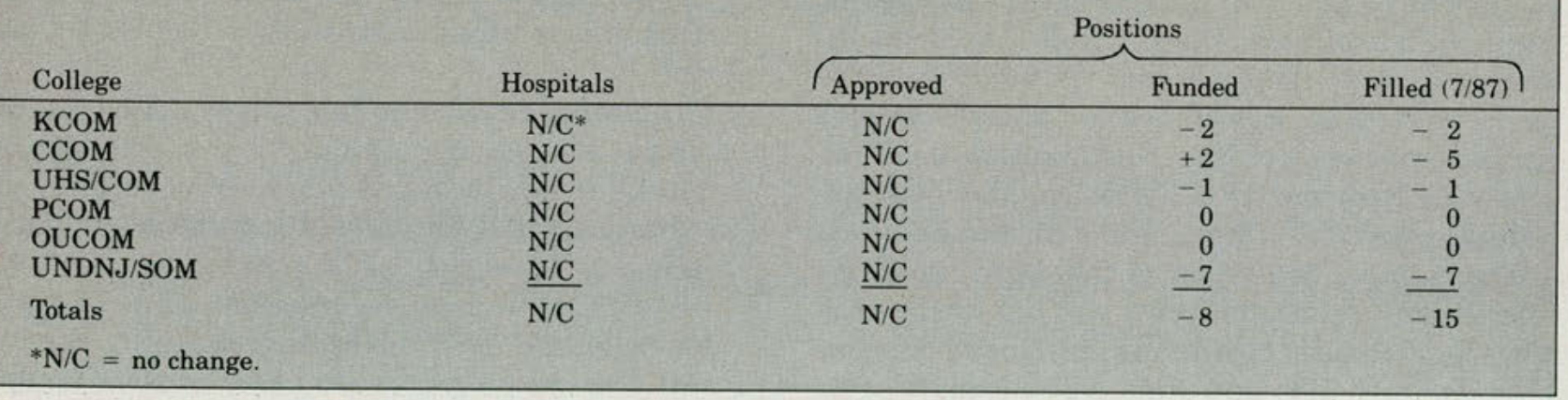

\section{Other college-sponsored internships}

As college-based internships represent only one aspect of intern programs sponsored by colleges of osteopathic medicine, it is important to monitor activity in those college programs approved prior to Board Memorandum B-March/84-3. Table 2 provides a general summary for this category of college internships, and Table 2A summarizes changes since May 1986.

Table 3 presents statistics inclusive of all college- sponsored intern training programs. Changes since June 1986 are indicated in parentheses.

It is important to consider activity in internship development in relation to college-sponsored programs to determine their relative impact. We find that colleges now sponsor 398 intern positions out of a total of 1,600 positions or 25 percent of all internships nationwide. Of these, 197 are new since 1983. Figure 2 compares college intern positions with the total set of positions. 


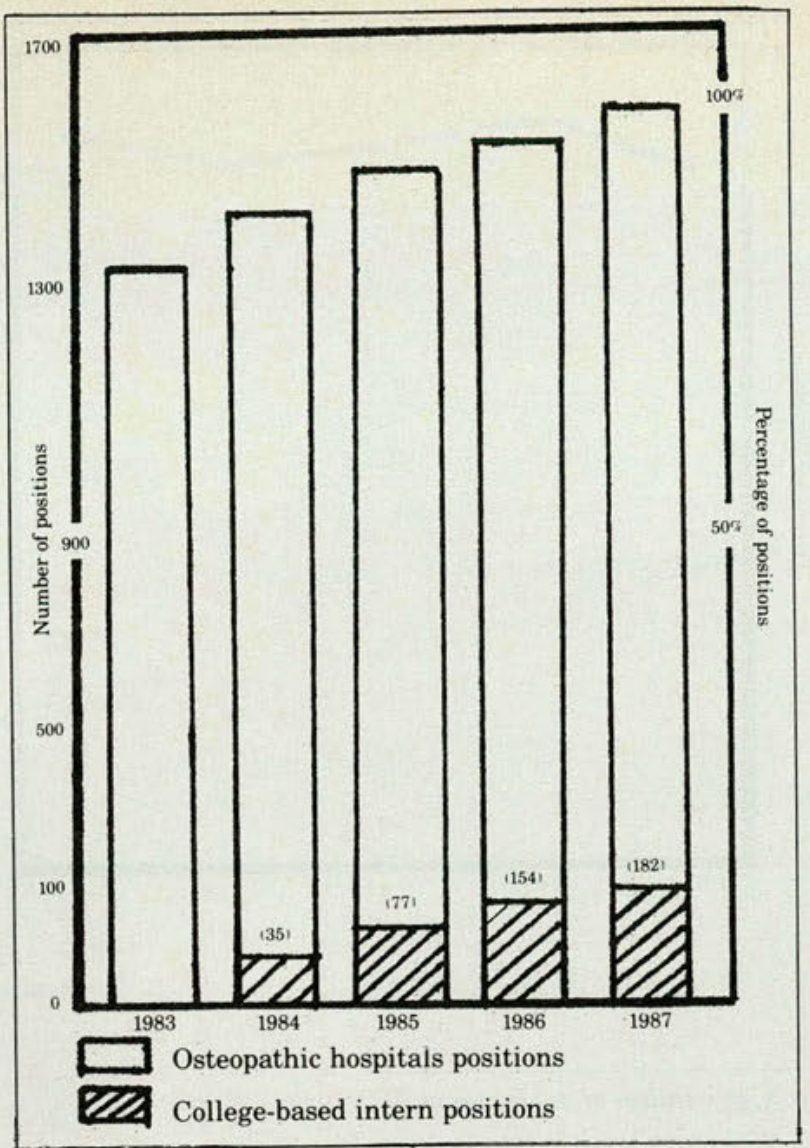

Fig. 1. AOA-approved intern positions. (Numbers do not include military interns.)

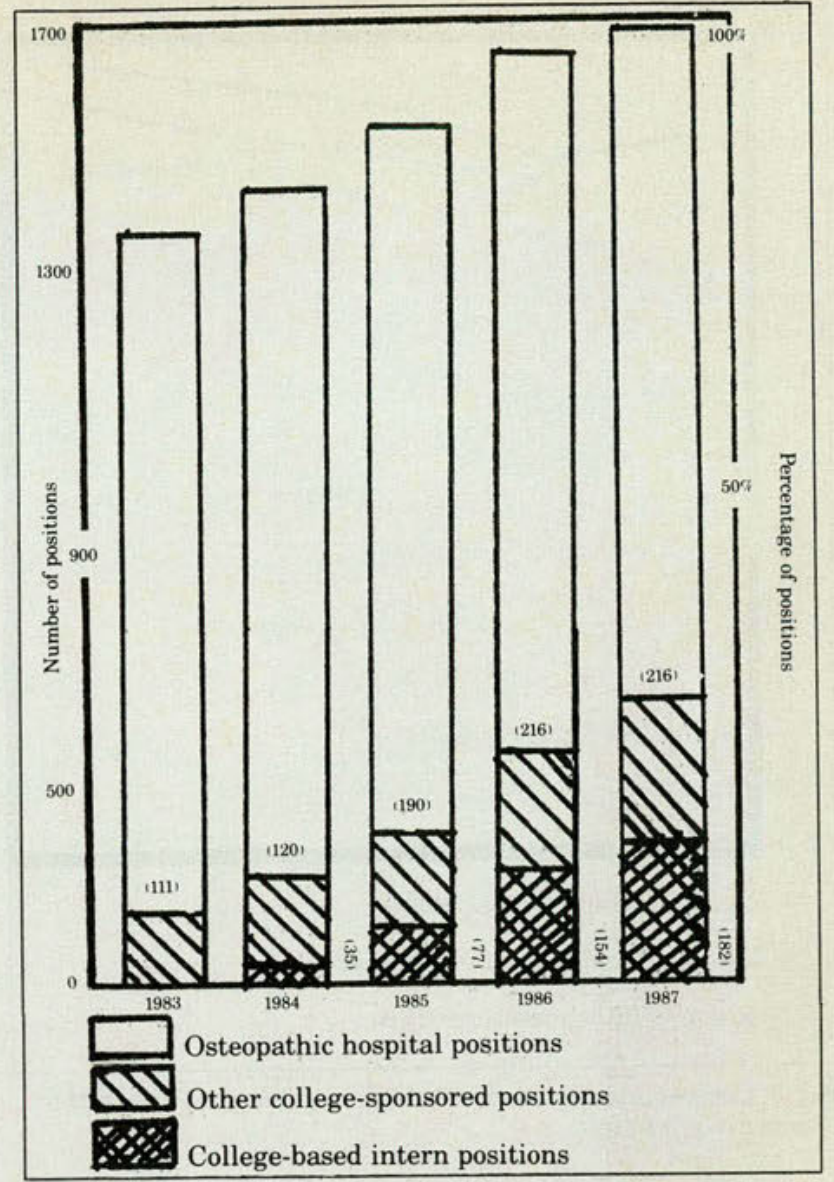

Fig. 2. AOA-approved intern positions in colleges and hospitals.

\begin{tabular}{|c|c|c|c|c|}
\hline \multirow[b]{2}{*}{ College } & \multirow[b]{2}{*}{ Hospitals } & \multicolumn{3}{|c|}{ Positions } \\
\hline & & Approved & Funded & Filled $(7 / 87)$ \\
\hline COMP & $2(-1)^{*}$ & $12(-13)$ & $12(+4)$ & $12(+4)$ \\
\hline SECOM & 1 & 10 & $6(+2)$ & $6(+2)$ \\
\hline CCOM & 5 & 86 & $65(+2)$ & $56(-5)$ \\
\hline UOMHS & 0 & 0 & 0 & \\
\hline UNE/COM & $1(+1)$ & $1(+1)$ & $1(+1)$ & $1(+1)$ \\
\hline MSU/COM & $2(+1)$ & $12(+4)$ & $7(+3)$ & $7(+3)$ \\
\hline $\mathrm{KCOM}$ & 1 & 21 & $11(-2)$ & $11(-2)$ \\
\hline UHS/COM & 1 & 14 & $10(-1)$ & $10(-1)$ \\
\hline UMDNJ/SOM & 3 & 60 & $48(-7)$ & $48(-7)$ \\
\hline NYCOM & 7 & $93(+14)$ & $81(+2)$ & $77(+16)$ \\
\hline OUCOM & 1 & 5 & 5 & \\
\hline OCOMS & 0 & 0 & 0 & 0 \\
\hline PCOM & $4(+2)$ & $54(+12)$ & $54(+12)$ & $52(+10)$ \\
\hline TCOM & $1(+1)$ & $5(+5)$ & 0 & 0 \\
\hline WVSOM & 5 & $23(+3)$ & $23(+3)$ & $20(+6)$ \\
\hline Totals & $34(+4)$ & $396(+26)$ & $323(+19)$ & $305(+27)$ \\
\hline${ }^{*}$ Changes since & & & & \\
\hline
\end{tabular}

\begin{tabular}{|c|c|c|c|c|c|}
\hline \multirow[b]{2}{*}{ Year } & \multirow{2}{*}{$\begin{array}{l}\text { Total \# } \\
\text { graduates } \\
\text { (no.) }\end{array}$} & \multirow[b]{2}{*}{$\begin{array}{l}\text { Approved } \\
\text { (no.) }\end{array}$} & \multicolumn{2}{|c|}{ Positions } & \multirow{2}{*}{$\begin{array}{l}\text { Graduates } \\
\text { matched } \\
(\%)\end{array}$} \\
\hline & & & $\begin{array}{l}\text { Available } \\
\text { (no.) }\end{array}$ & $\begin{array}{l}\text { Filled }(7 / 87)) \\
\text { (no.) }\end{array}$ & \\
\hline 1983 & 1,328 & 1,313 & N/A & 1,146 & 86 \\
\hline 1984 & 1,304 & 1,408 & 1,283 & 1,191 & 91 \\
\hline 1985 & 1,484 & 1,525 & 1,309 & 1,291 & 87 \\
\hline 1986 & 1,558 & 1,642 & 1,379 & 1,346 & 86 \\
\hline 1987 & 1,579 & 1,660 & 1,387 & 1,338 & 85 \\
\hline
\end{tabular}




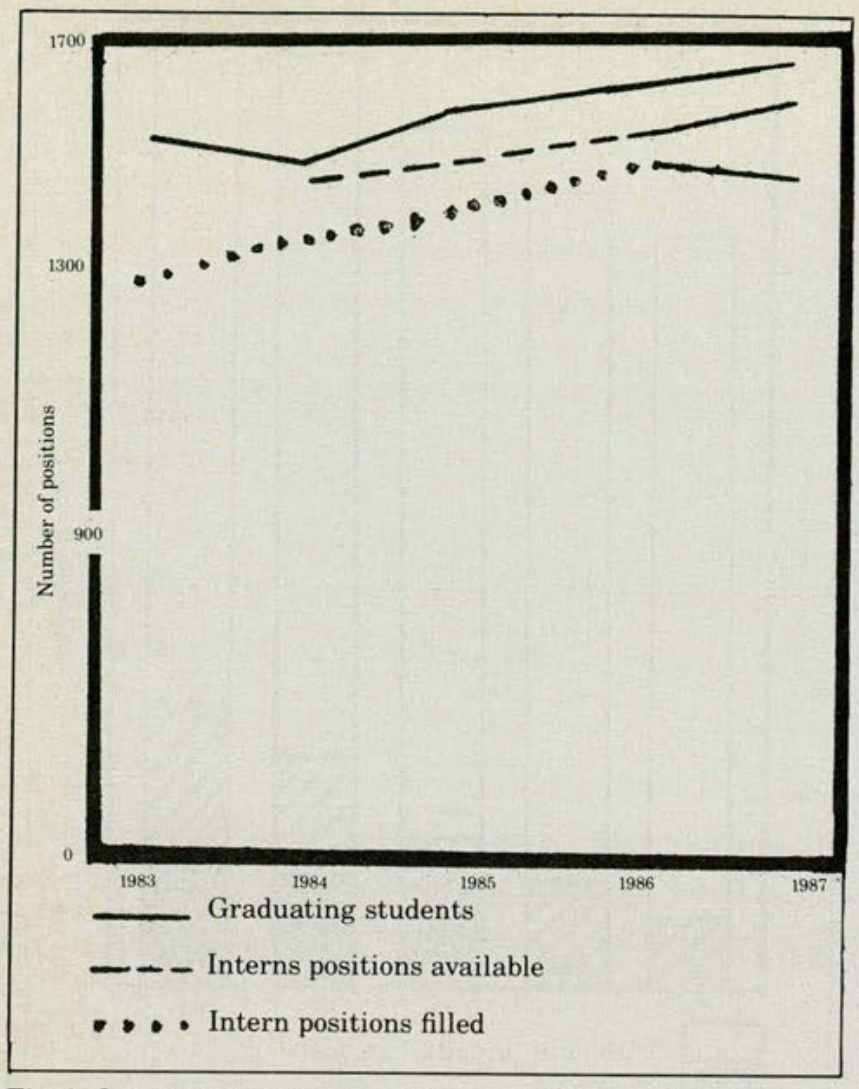

Fig. 3. Comparison of growth in intern positions in relation to the number of graduates.

Osteopathic hospitals generated 1,262 internship positions, as of July 1987 . This represents 75 percent of the total number of AOA-approved positions. As of July 1987, colleges sponsored 396 approved positions for 24 percent of the total, an increase of 22 positions since May 1986. At the same time as positions sponsored by colleges are increasing, positions sponsored by osteopathic hospitals are decreasing, so that all growth is in the college sector.

\section{Growth comparison between internships and gra- duates}

One question is "how does the existence of collegebased internships affect the needs of graduates?" Students are graduating in increasing numbers. Table 4 summarizes this growth in relationship to the growth in the number of intern positions.

The growth comparison between approved and available intern slots and graduating seniors is summarized in Figure 3. Growth is defined as the actual increase in numbers per year. (The figures do not include AOA-approved military programs.)

The actual number of graduates being placed in AOA-approved programs has decreased this year although the percentage of graduates in AOA-ap-

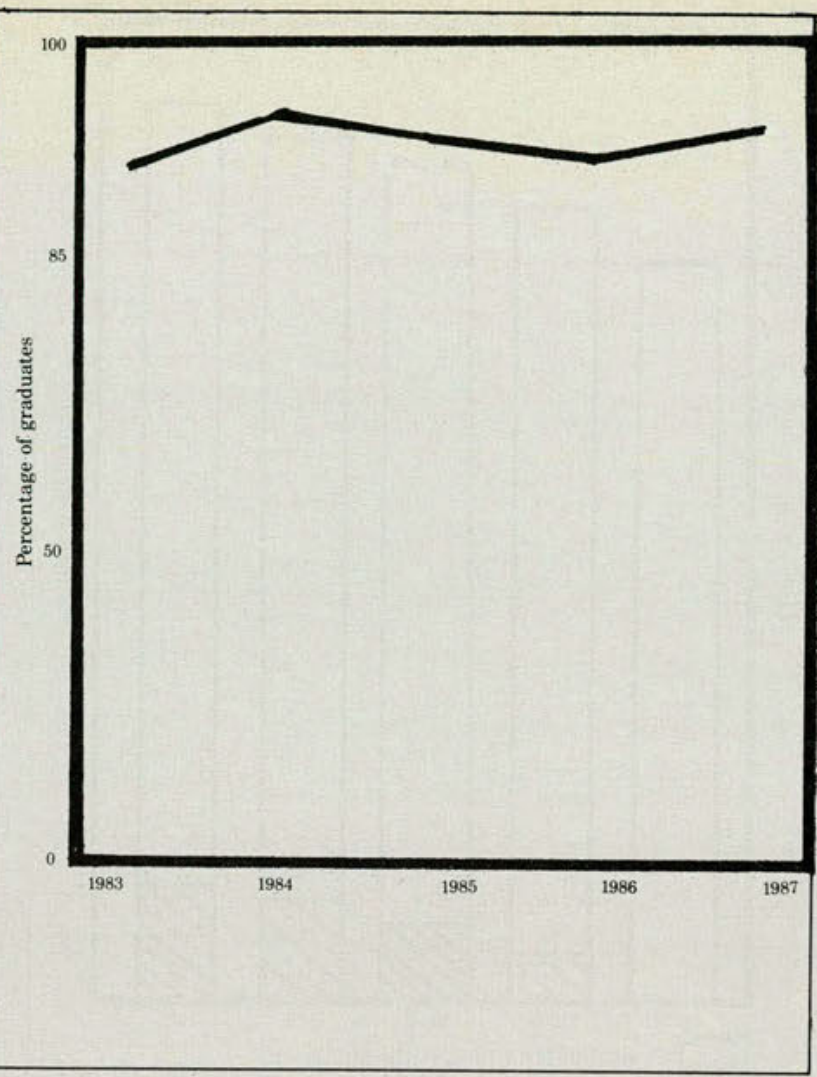

Fig. 4. Percentage of graduates in AOA-approved positions.

proved positions has increased, as shown in Figure 4.

\section{Conclusions}

(1) College-sponsored internship programs continue to contribute significantly to the growth in the number of AOA-approved intern positions. The overall percentage of college-sponsored positions has risen to 25 percent of the total pool.

(2) A significant number of colleges continue to respond to Board Memorandum B-March/84-3 and are establishing and expanding college-based internship programs.

(3) The total number of internship positions in traditional, free-standing programs is declining, although new programs are still being initiated.

(4) The most significant growth has been in college-based programs in allopathic and mix-staffed institutions.

(5) The AOA should continue to encourage and facilitate the development of intern positions by both osteopathic hospitals and colleges of osteopathic medicine.

Dr. Ward is director of the AOA Department of Education, Chicago, Illinois. 